\title{
Prevalence of Levator Ani Defects in Urogynecological Patients
}

\section{Prävalenz von Levator-ani-Defekten bei urogynäkologischen Patientinnen}

Authors

Affiliations
S. Albrich ${ }^{1}$, K. Rommens ${ }^{1}$, J. Steetskamp ${ }^{1}$, V. Weyer ${ }^{2}$, G. Hoffmann ${ }^{1}$, C. Skala ${ }^{1}$, E. Zahn ${ }^{3}$

${ }^{1}$ Johannes-Gutenberg-University Mainz, Department of Obstetrics and Gynecology, Mainz

2 Johannes-Gutenberg-University Mainz, Institute of Medical Biostatistics, Epidemiology and Informatics (IMBEI), Mainz

${ }^{3}$ Klinikum Kempten, Obstetrics and Gynecology, Kempten
Key words

- uterine prolapse

- sonography

- urinary incontinence

Schlüsselwörter

- Uterusprolaps

- Ultraschall

- Harninkontinenz

Deutschsprachige Zusatzinformationen online abrufbar unter: www.thieme-connect.de/ ejournals/toc/gebfra $\begin{array}{ll}\text { received } & 28.6 .2014 \\ \text { revised } & 2.11 .2014 \\ \text { accepted } & 2.11 .2014\end{array}$

Bibliography

DOI http://dx.doi.org/ 10.1055/s-0034-1396180

Geburtsh Frauenheilk 2015; 75 : 51-55 (c) Georg Thieme

Verlag KG Stuttgart · New York . ISSN 0016-5751

\section{Correspondence}

\section{Dr. med. Stefan Bernt Albrich}

Johannes-Gutenberg-University

Mainz

Department of Obstetrics

and Gynecology

Langenbeckstraße 1

55131 Mainz

albrich@uni-mainz.de

\section{Abstract}

$\nabla$

Introduction: Defects of the levator ani muscle complex could represent a pathophysiological link between vaginal birth trauma and urogynecological symptoms many years later. The aim of our study was to determine the prevalence of levator ani muscle defects using 3D or 4D ultrasound and palpation in urogynecological patients. Material and Methods: Urogynecological patients were retrospectively investigated using 3D or 4D ultrasound. Clinical examination consisted of palpation and 3D or 4D imaging of the levator ani muscle.

Results: A total of 319 women were included in the analysis. Mean age was 64.9 years, average parity was 2.1. Stress incontinence was present in $50.8 \%$, overactive bladder symptoms in $69.3 \%$ and pelvic organ prolapse in $42.3 \%$ of patients. A levator ani defect was found on ultrasound in 76 patients $(23.8 \%)$ and on palpation in 64 women (20.0\%). In the group of patients with pelvic organ prolapse, levator ani defects were found in 32.6\% of patients using ultrasound and in $26.7 \%$ of patients using palpation. The odds ratio (OR) for levator ani defects in women with pelvic organ prolapse was 2.3 (95\% CI [CI: confidence interval]: 1.36-3.88], $\mathrm{p}=0.002$ ).

Conclusion: In a cohort of urogynecological patients seen at a tertiary urogynecological unit, the prevalence of levator ani defects was significantly higher in women with pelvic organ prolapse compared to women with stress incontinence or urge symptoms.

\section{Zusammenfassung \\ $\nabla$}

Einleitung: Levatordefekte scheinen die pathophysiologische Lücke zwischen der Vaginalgeburt und späterer urogynäkologischer Symptome zu schließen. Ziel dieser Untersuchung war es, die Prävalenz von Levatordefekten sowohl mittels 3D- bzw. 4-D-Ultraschall (D: dimensional) als auch durch Palpation bei urogynäkologischen Patientinnen zu bestimmen.

Material und Methoden: Retrospektiv wurden urogynäkologische Patientinnen untersucht, bei denen ein 3-D- bzw. 4-D-Ultraschall durchgeführt wurde. Die klinische Beurteilung erfolgte palpatorisch am Muskelansatz. Zur sonografischen Begutachtung des Levatorstatus wurde das 3-D- bzw. 4-D-Volumen auf Höhe der Hiatusenge analysiert.

Ergebnisse: Es wurden die Daten von 319 Patientinnen ausgewertet. Das durchschnittliche Alter betrug 64,9 Jahre, die durchschnittliche Parität lag bei 2,1. Die Prävalenz der Belastungsinkontinenz betrug 50,8\%, des Dranges 69,3\% und Deszensus $42,3 \%$. Sonografisch konnte ein Levatordefekt in 76 Fällen (23,8\%) und mittels Palpation in 64 Fällen (20,0\%) festgestellt werden. In der Gruppe der Senkungspatientinnen betrug die Prävalenz von Levatordefekten sonografisch $32,6 \%$ und palpatorisch $26,7 \%$. Für sonografisch detektierte Levatordefekte konnte mit einer Odds Ratio (OR) von 2,3 (95\%-KI [KI: Konfidenzintervall] $1,36-3,88$ ], $p=0,002)$ ein statistisch signifikanter Einfluss für einen Deszensus festgestellt werden. Schlussfolgerung: In einem Kollektiv urogynäkologischer Patientinnen ist die Prävalenz von Levatordefekten bei Frauen mit Deszensus höher als bei Frauen mit Drangbeschwerden oder Belastungsinkontinenz. 


\section{Introduction}

$\nabla$

Urogynecological complaints such as urinary incontinence, overactive bladder/urge or pelvic organ prolapse are increasingly common, particularly in countries with higher life expectancy $[1,2]$. The risk of requiring surgery for urinary incontinence or pelvic organ prolapse is reported to be between 11.8-20\% [3-5]. The pelvic floor musculature is the most important functional anatomy of the female pelvis. A detailed urogynecological examination includes careful assessment of pelvic floor muscle strength [6]. Targeted pelvic floor training plays an important role in the conservative management of urinary and fecal incontinence [7].

Use of palpation to determine the presence of muscular defects of the levator ani complex after vaginal birth was first described in the 1940s [8]. Several decades later, modern imaging techniques such as magnetic resonance imaging $[9,10]$ and 3D sonography of the pelvis [11] have resulted in a renewed focus on pelvic floor musculature. These more recent techniques have provided evidence for the impact of vaginal birth, particularly forceps birth, on pelvic floor musculature and highlighted vaginal birth as a major cause of defects of the pelvic musculature [10-12]. In addition to the palpatory evaluation of the pelvic floor musculature $[6,13]$, imaging methods such as urogenital sonography or magnetic resonance imaging are becoming increasingly important in urogynecological examinations [9,14-20]. In recent years, sonography has become an indispensable part of standard urogynecological diagnostics as it is widely available, requires only a limited number of staff and is comparatively inexpensive [19, 21 . The urogenital hiatus and the levator ani complex can be displayed using modern 3D and 4D techniques [21].

Defects of the levator ani complex appear to be the pathophysiological link between vaginal birth and the emergence of urogynecological symptoms many years later $[11,22]$. Several studies have demonstrated the connection between levator avulsion and pelvic organ prolapse [22]. Levator ani defects also appear to be a significant risk factor for recurrence after pelvic floor surgery $[23,24]$.

The aim of this study was to investigate the prevalence of levator ani defects using 3D sonography and palpation in a cohort of urogynecological patients. Moreover, the study also aimed to investigate the relationship between levator ani muscle defects and clinical symptoms such as stress incontinence, overactive bladder and prolapse.

\section{Material and Methods}

$\nabla$

\section{Patient population}

Retrospective analysis was done of the data of 319 patients who presented to our urogynecological clinic between March 2011 and June 2013 on an outpatient basis. Only women who had 3D or 4D sonography of the pelvic floor were included in the study. Women who had previously undergone surgery for incontinence or prolapse were excluded from the study.

\section{Approach}

After taking a detailed medical history including a careful description of symptoms, the patient was examined clinically with palpatory assessment of the levator ani muscle, followed by 3D or 4D perineal ultrasound.

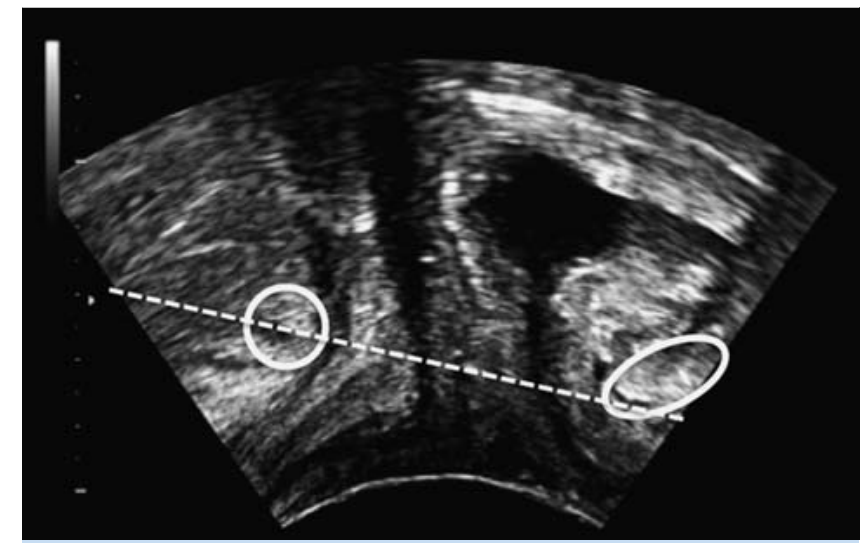

Fig. 1 Standard mid-sagittal plane on 2D sonography. Image orientation done according to the recommendations of the German, Austrian and Swiss medical association shows the symphysis (oval) on the right and the puborectal sling of the levator ani (circle) dorsal to the anorectum on the left. Caudal structures are depicted in the lower half of the image. The levator hiatus, which is the standard plane in 3D sonography, is orthogonal to the mid-sagittal plane at the level of the shortest distance between the symphysis and the puborectal sling (dotted line).

During the medical history, the patient was asked about bladder symptoms, using the German Pelvic Floor Questionnaire [25], to determine whether the patient had urge symptoms or stress urinary incontinence.

Objective prolapse findings were used rather than subjective symptoms of proplapse. Findings were based on speculum examination, with pelvic organ prolapse defined according to standard recommendations as prolapse of the anterior, middle or posterior compartment lower than $-1 \mathrm{~cm}$ above the hymenal plane (equivalent to POP-Q [Pelvic Organ Prolapse Quantification System] stage $\geq 2$ ) on maximum Valsalva maneuver [26,27].

During clinical palpation, the index finger followed the distal muscular part of the levator ani muscle, the puborectalis muscle, from dorsal to its point of insertion on the inferior pubic ramus. The presence of muscle tissue at the inferior pubic ramus bilaterally was assessed during pelvic floor contraction or at rest in women with acontractile pelvic floor muscles [28].

\section{Ultrasound examination}

Ultrasound examination was done with the patient in the lithotomy position after palpation and spontaneous voiding of the bladder. Ultrasound was done using a GE Voluson $\mathrm{e}^{\circledR}$ system and a 3D abdominal probe (curved array probe, RAB 4-8-RS, 48.5 MHz). The probe was positioned along the longitudinal axis of the patient perpendicular to the introitus for mid-sagittal imaging of the pelvic floor. This is the standard plane used in 2D ultrasound and shows the symphysis on the right and the anechoic urethra, the bladder, the anterior vaginal wall and the anorectum, in accordance with the recently revised S2k guidelines of the German, Austrian and Swiss medical association [20]. The hyperechoic puborectalis muscle of the levator ani complex is dorsal to the anorectal junction ( $\bullet$ Fig. 1).

The patient was requested to contract her pelvic floor, relax it again and then do a maximum Valsalva maneuver. The 3D ultrasound volume sequences were stored electronically as 3D or 4D images for later processing.

Sonographic assessment of levator ani status based on stored ultrasound images was subsequently done offline by the same in- 

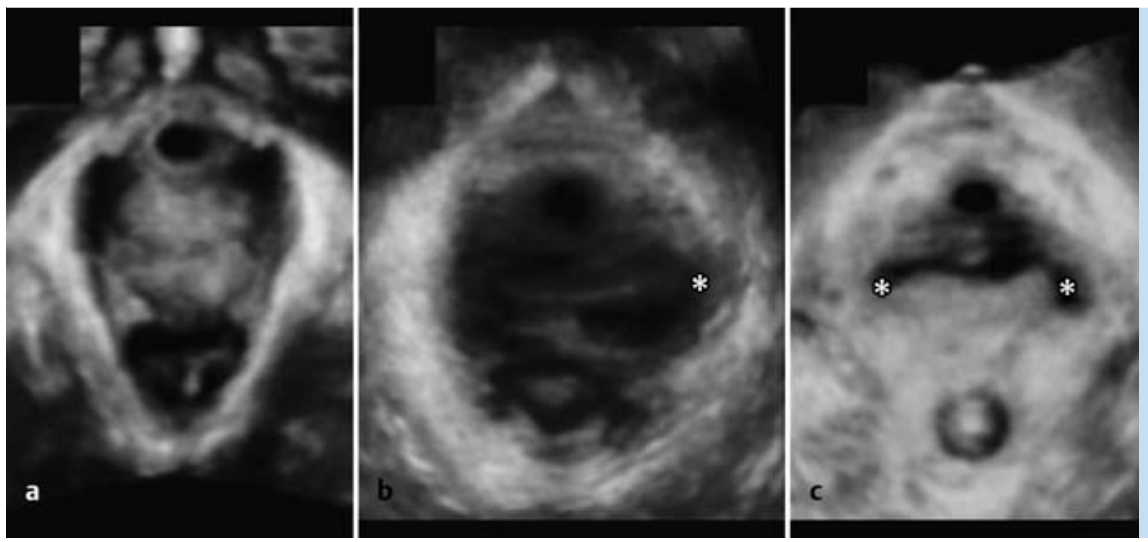

Fig. 2 a to $\mathbf{c}$ "Rendered volume" of the "hiatal plane": the "rendered volume" is given as a semitransparent depiction of all pixels (or voxels) of a defined volume sequence at the level of the levator hiatus. Image orientation was from caudal to cranial. a Intact levator ani: image shows the hyperechoic puborectal sling with bilateral ventral muscle attachments on the inferior pubic ramus (above) at the anorectum (below).

b Left-sided levator ani defect: intact point of insertion on the right side and missing muscle attachment on the left (marked with a *).

c Bilateral levator ani defect: no point of insertion of the hyperechoic puborectal sling bilaterally on the inferior pubic ramus (marked with a *).

vestigator using image processing software (4D View, GE Healthcare) with standardization performed in plane $C$.

In the mid-sagittal plane the orthogonal plane of minimal hiatal dimensions according to Dietz defines the shortest distance between the puborectalis muscle and the symphysis [29]. A levator ani defect was defined as discontinuity in the rendered volume of the hyperechoic puborectalis muscle of the levator ani complex at the inferior pubic ramus at maximum contraction of the pelvic floor or at rest if the pelvic floor was acontractile ( $\odot$ Figs. 2 a to c) [30].

\section{Statistical analysis}

Patient age was given as mean, standard deviation, minimum and maximum. For statistical analysis, categorical data were described using relative and absolute frequencies. This included the prevalence of a levator ani defect. Bar graphs were used for the graphical representation of data. The exact 95\% confidence intervals $(\mathrm{CI})$ are given for individual prevalences.

Univariate logistic regression analysis was carried out to assess the impact of different influencing variables (stress incontinence [SI], prolapse and urge) on the target variables "levator ani defect on ultrasound" or "levator ani defect on palpation". Odds ratio (OR), the 95\% CI and the respective p-values were calculated. Bonferroni correction was used because of multiple testing, and overall significance was set to $5 \%$; this means that a p-value $<0.05 / 6=0.008$ was considered significant.

\section{Results}

\section{$\nabla$}

\section{Patient population}

The data of 319 patients were retrospectively analyzed. Average age of the patients was 64.9 years (29-94 years, standard deviation 2.12 ). Mean parity was $2.1(0-7) ; 4.7 \%$ of patients were nulliparous ( Table 1).

We divided the patients into groups based on the three main symptoms: prolapse, stress incontinence and urge symptoms ( Fig. 3). A total 135 patients (42.3\%; 95\% CI: 36.83-47.95) had prolapse of the pelvic organs, 162 women (50.8\%; 95\% CI: 45.16-56.40) complained of stress incontinence, and 221 patients had urge symptoms (69.3\%; 95\% CI: 63.90-74.30).

\section{Prevalence of levator ani defects}

on ultrasound and palpation

On sonography, a levator ani defect was found in 76 patients (23.8\%; 95\% CI: 19.26-28.89); in 29 patients (9.1\%; 95\% CI 6.1712.79) this defect was bilateral.
Table 1 Characteristics of the cohort of urogynecological patients.

\begin{tabular}{|c|c|c|}
\hline Study population & 319 & $100 \%$ \\
\hline Mean age (range) & 64.9 years & $29-94$ years \\
\hline Postmenopausal patients & 271 & $85.0 \%$ \\
\hline Nulliparous & 15 & $4.7 \%$ \\
\hline Primiparous & 84 & $26.3 \%$ \\
\hline Para 2 & 125 & $39.2 \%$ \\
\hline Para 3 & 67 & $21.0 \%$ \\
\hline Para 4 & 16 & $5.0 \%$ \\
\hline > Para 4 & 12 & $3.8 \%$ \\
\hline
\end{tabular}

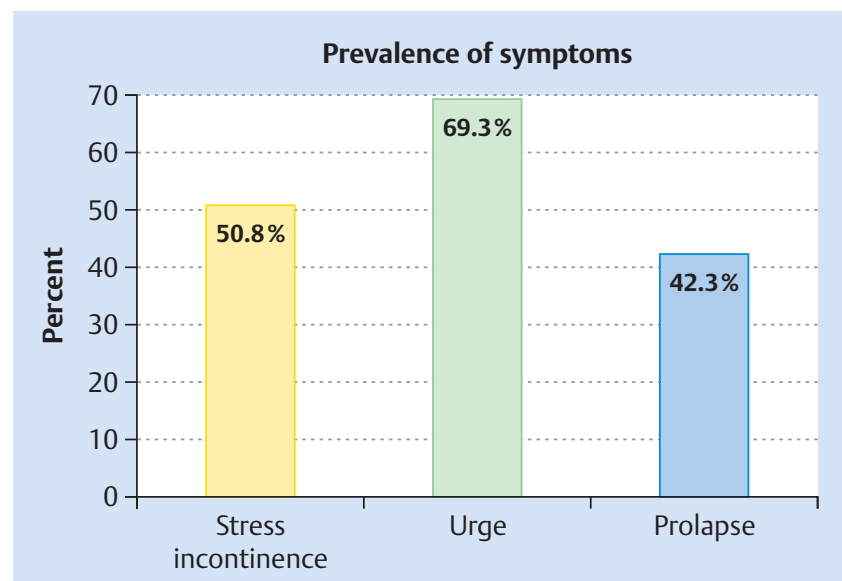

Fig. 3 Prevalence of the three main symptoms: prolapse (42.3\%), stress incontinence $(50.8 \%)$ and urge $(69.3 \%)$.

On palpation, a defect of the levator ani muscle was found in 64 cases of the patient population (20.0\%; 95\% CI 15.81-24.88); in 31 of these women $(9.7 \%$; $95 \% \mathrm{CI}: 6.70-13.51)$ the defect was bilateral.

\section{Prevalence of levator ani defects correlated to symptoms}

In the group of patients with urge symptoms, 43 patients $(19.5 \%$; 95\% CI: 14.45-25.30) were found to have a levator ani defect on palpation and 50 (22.6\%; 95\% CI: 17.28-28.72) had a levator ani defect on ultrasound.

In the group of patients with stress incontinence symptoms, 26 patients (16.0\%; 95\% CI: 10.76-22.63) had a levator ani defect detected on palpation, and 33 patients (20.4\%; 95\% CI: $14.46-$ 27.40) had a levator ani defect on ultrasound. 


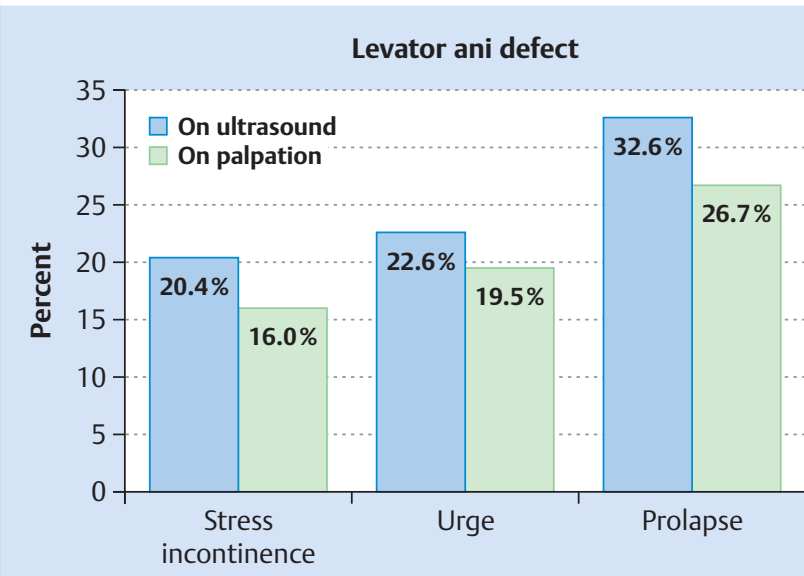

Fig. 4 In the group of patients with prolapse, a levator ani defect was detected on palpation in $26.7 \%$ of patients and a levator ani defect was found on ultrasound in $32.6 \%$ of patients.

In the group of patients with prolapse, 36 women $(26.7 \%$; $95 \% \mathrm{CI}$ : 19.43-34.96) had a levator ani defect which was detected on palpation, and 44 women (32.6\%; 95\% CI: 24.78-41.19) had a levator ani defect detected on ultrasound ( $\bullet$ Fig. 4).

Univariate logistic regression analysis only found a statistically significant impact on the target variable "levator ani defect on ultrasound" for the symptom "prolapse" (OR 2.3; 95\% CI: 1.36$3.88, \mathrm{p}=0.002$ ) but not for the symptoms "stress incontinence" or "urge" ( Table 2 ).

Univariate logistic regression analysis only showed a noticable value for the target variable "levator ani defect on palpation" in patients with prolapse (OR 2.0; 95\% CI: 1.16-3.53, p=0.013); however, after Bonferroni correction this did not reach statistical significance.

\section{Discussion \\ $\nabla$}

In our urogynecological patient population, a levator ani muscle defect was found in $23.8 \%$ of patients using 3D sonography and in $20.0 \%$ of patients using palpation. A higher prevalence of detected levator ani muscle defects was found in the group with prolapse, both on ultrasound and on palpation (32.6 and 26.7\%, respectively), while the prevalence was similarly low, both in the group with stress incontinence (20.4 and $16.0 \%$, respectively) and in the group with urge symptoms (22.6 and $19.5 \%$, respectively).

The prevalence of urogynecological symptoms in patients visiting a pelvic floor center was comparable with the figures pub- lished by Dietz et al. [22], although the percentage of patients whom we diagnosed with stress incontinence was somewhat lower (50.8\% compared to $76 \%$ ) and the percentage of patients whom we diagnosed with prolapse was slightly higher $(42.3 \%$ compared to $38 \%$ ). The mean age of our patients was slightly higher with 64.9 years, but mean parity was the same (2.1). The differences in the prevalence of symptoms could be due to the different ethnicity of the investigated patients, the higher mean age of our patients or the difference in how health services are structured in Australia and Germany.

Although pelvic floor training is an important and effective strategy in the conservative management of urge symptoms and stress incontinence [7], we found no statistical correlation with levator ani defects for those two groups in our patient population [31]. "Levator ani defects" or "levator avulsion" are defects of the puborectalis muscle, i.e. of the distal part of the levator ani complex and not necessarily of the entire levator ani complex. In contrast to the more proximal muscles, this muscle segment is subjected to the greatest muscle stretch during vaginal delivery [ 10 , 32].

The connection between levator ani defects and prolapse has been confirmed in other studies [22,31]. Mechanically, the muscular limitation of the genital hiatus makes it the "largest hernial portal of the human body" [33] through which the pelvic organs can prolapse. Any structural weakness of this muscular limitation can lead to excessive widening of the genital hiatus, also referred to as "hiatal ballooning", which is known to be correlated with levator ani defects [34]. Along with levator ani defects, this is considered an independent parameter for prolapse [35].

The inferiority of clinical palpation compared to 3D ultrasound has been previously described in the literature [28], although correct palpatory assessment of levator ani status appears to depend on the experience of the investigator [36].

Acontractile pelvic floor musculature makes the manual assessment of levator ani integrity more difficult. The compensatory contraction of superficial muscle layers such as the bulbospongiosus muscle or of deeper muscle layers such as the pubococcygeus muscle can potentially lead to misinterpretation. Although, in contrast to ultrasound diagnosis in prolapse patients, the clinical palpation of levator ani defects did not reach statistical significance, a statistical trend was discernable, which could potentially reach statistical significance if the number of study participants were larger.

As only urogynecological patients who have had 3D or 4D ultrasound were included in this analysis, it is not possible to exclude inclusion bias.

A further limitation of our analysis is that both clinical palpation and ultrasound diagnosis were both carried out by the same investigator.

Table 2 A statistically significant impact on the target variable "levator ani defect on ultrasound" was only found for prolapse.

\begin{tabular}{|c|c|c|c|c|}
\hline Dependent variable & Independent variables & OR & $95 \% \mathrm{Cl}$ & p-value \\
\hline \multirow[t]{3}{*}{ Levator ani defect on ultrasound } & Stress incontinence yes vs. no & 0.68 & $0.40-1.14$ & 0.142 \\
\hline & Prolapse yes vs. no & 2.28 & $1.36-3.88$ & 0.002 \\
\hline & Urge yes vs. no & 0.81 & $0.47-1.40$ & 0.450 \\
\hline \multirow[t]{3}{*}{ Levator ani defect on palpation } & Stress incontinence yes vs. no & 0.60 & $0.34-1.04$ & 0.071 \\
\hline & Prolapse yes vs. no & 2.03 & $1.16-3.53$ & 0.013 \\
\hline & Urge yes vs. no & 0.89 & $0.49-1.59$ & 0.685 \\
\hline
\end{tabular}




\section{Conclusion}

\section{$\nabla$}

The prevalence of levator ani defects in our population of urogynecological patients was $23.8 \%$. Patients with prolapse had statistically significantly more muscular defects of the pelvic floor. In contrast, the prevalence of levator ani defects did not differ between women with stress incontinence and women with urge symptoms.

Levator ani defects are found more frequently with 3D ultrasound compared to palpation alone. Nevertheless, although ultrasound appears to be superior to palpation alone for the detection of levator ani defects, our own clinical experience has shown that urogynecological diagnosis requires that ultrasound be done in combination with palpatory assessment of the pelvic floor musculature.

The fact that the risk of recurrence after prolapse surgery is significantly higher in patients with levator ani defects is of particular clinical importance $[23,24,37]$. Presurgical determination of levator ani defects could help ensure that groups at special risk of recurrence are identified preoperatively. In future, this could justify the targeted use of alloplastic mesh implants in a primary setting in patients with levator ani defects.

\section{Conflict of Interest}

$\nabla$

Stefan Albrich has received speaker's fees from OmniaMed and Astellas.

Karlien Rommens, Joscha Steetskamp, Veronika Weyer, Gerald Hoffmann, Christine Skala, Eva Zahn report no conflicts of interest in connection with this article.

\section{References}

1 Rortveit G, Brown JS, Thom DH et al. Symptomatic pelvic organ prolapse: prevalence and risk factors in a population-based, racially diverse cohort. Obstet Gynecol 2007; 109: 1396-1403

2 Chow D, Rodriguez LV. Epidemiology and prevalence of pelvic organ prolapse. Curr Opin Urol 2013; 23: 293-298

3 Fialkow MF, Newton KM, Lentz GM et al. Lifetime risk of surgical management for pelvic organ prolapse or urinary incontinence. Int Urogynecol J Pelvic Floor Dysfunct 2008; 19: 437-440

$4 \mathrm{Wu}$ JM, Matthews CA, Conover MM et al. Lifetime risk of stress urinary incontinence or pelvic organ prolapse surgery. Obstet Gynecol 2014; 123: 1201-1206

5 Smith FJ, Holman CD, Moorin RE et al. Lifetime risk of undergoing surgery for pelvic organ prolapse. Obstet Gynecol 2010; 116: 1096-1100

6 Bo K, Finckenhagen HB. Vaginal palpation of pelvic floor muscle strength: inter-test reproducibility and comparison between palpation and vaginal squeeze pressure. Acta Obstet Gynecol Scand 2001; 80: $883-887$

7 Reisenauer C, Riegel K, Hübner M et al. Die Wirksamkeit des Beckenbodentrainings bei Patientinnen mit Stressharninkontinenz - Eine prospektiv-randomisierte dreiarmige Vergleichsstudie. Geburtsh Frauenheilk 2008; 68: S01

8 Gainey HL. Post-partum observation of pelvic tissue damage. Am J Obstet Gynecol 1943; 46: 457-466

9 Hoyte L, Schierlitz L, Zou K et al. Two- and 3-dimensional MRI comparison of levator ani structure, volume, and integrity in women with stress incontinence and prolapse. Am J Obstet Gynecol 2001; 185: 1119

10 DeLancey JO, Kearney $R$, Chou $Q$ et al. The appearance of levator ani muscle abnormalities in magnetic resonance images after vaginal delivery. Obstet Gynecol 2003; 101: 46-53

11 Dietz HP, Lanzarone V. Levator trauma after vaginal delivery. Obstet Gynecol 2005; 106: 707-712

12 Tunn R, DeLancey JO, Howard D et al. MR imaging of levator ani muscle recovery following vaginal delivery. Int Urogynecol J Pelvic Floor Dysfunct 1999; 10: 300-307
13 Peschers UM, Gingelmaier A, Jundt $K$ et al. Evaluation of pelvic floor muscle strength using four different techniques. Int Urogynecol J Pelvic Floor Dysfunct 2001; 12: 27-30

14 Dietz HP, Wilson PD, Clarke B. The use of perineal ultrasound to quantify levator activity and teach pelvic floor muscle exercises. Int Urogynecol J Pelvic Floor Dysfunct 2001; 12: 166-168; discussion 168-169

15 Braekken IH, Majida M, Engh ME et al. Test-retest reliability of pelvic floor muscle contraction measured by $4 \mathrm{D}$ ultrasound. Neurourol Urodyn 2009; 28: 68-73

16 Yang SH, Huang WC, Yang SY et al. Validation of new ultrasound parameters for quantifying pelvic floor muscle contraction. Ultrasound Obstet Gynecol 2009; 33: 465-471

17 Delancey JO, Sørensen HC, Lewicky-Gaupp Cet al. Comparison of the puborectal muscle on MRI in women with POP and levator ani defects with those with normal support and no defect. Int Urogynecol J 2012; 23: 73-77

18 Naumann G, Kölbl H. Current developments and perspectives on the diagnosis and treatment of urinary incontinence and genital prolapse in women. Geburtsh Frauenheilk 2012; 72: 202-210

19 Tunn $R$, Schär G, Peschers $U$ et al. Updated recommendations on ultrasonography in urogynecology. Int Urogynecol J Pelvic Floor Dysfunct 2005; 16: 236-241

20 Arbeitsgemeinschaft der Wissenschaftlichen Medizinischen Fachgesellschaften (AWMF). S2k-Leitlinie: Sonographie im Rahmen der urogynäkologischen Diagnostik - AWMF 015/055. 12/2013. Online: http:// www.awmf.org/uploads/tx_szleitlinien/015-0551_S2k_Sonographie_ urogynäkologische_Diagnostik_2013-12_01.pdf; last access: 31.12.2013

21 Albrich S, Laterza R, Kölbl H. Stellenwert der 2D- und 3D-Perineal-Sonografie in der Urogynäkologie. Frauenheilkunde up2date 2011; 10: 317-329

22 Dietz HP, Simpson JM. Levator trauma is associated with pelvic organ prolapse. BJOG 2008; 115: 979-984

23 Dietz HP, Chantarasorn V, Shek KL. Levator avulsion is a risk factor for cystocele recurrence. Ultrasound Obstet Gynecol 2010; 36: 76-80

24 Model AN, Shek KL, Dietz HP. Levator defects are associated with prolapse after pelvic floor surgery. Eur J Obstet Gynecol Reprod Biol 2010; 153: 220-223

25 Baessler K, Kempkensteffen C. [Validation of a comprehensive pelvic floor questionnaire for the hospital, private practice and research]. Gynakol Geburtshilfliche Rundsch 2009; 49: 299-307

26 Bump RC, Mattiasson A, Bo K et al. The standardization of terminology of female pelvic organ prolapse and pelvic floor dysfunction. Am J Obstet Gynecol 1996; 175: 10-17

27 Persu C, Chapple CR, Cauni V et al. Pelvic Organ Prolapse Quantification System (POP-Q) - a new era in pelvic prolapse staging. J Med Life 2011; 4: $75-81$

28 Dietz HP, Hyland G, Hay-Smith J. The assessment of levator trauma: a comparison between palpation and 4D pelvic floor ultrasound. Neurourol Urodyn 2006; 25: 424-427

29 Dietz HP, Shek KL. Tomographic ultrasound imaging of the pelvic floor: Which levels matter most? Ultrasound Obstet Gynecol 2009; 33: 698703

30 Dietz HP, Moegni F, Shek KL. Diagnosis of levator avulsion injury: a comparison of three methods. Ultrasound Obstet Gynecol 2012; 40: 693698

31 Dietz HP, Kirby A, Shek KL et al. Does avulsion of the puborectalis muscle affect bladder function? Int Urogynecol J Pelvic Floor Dysfunct 2009; 20: 967-972

32 Lien KC, Mooney B, DeLancey JO et al. Levator ani muscle stretch induced by simulated vaginal birth. Obstet Gynecol 2004; 103: 31-40

33 Dietz HP. Geburtsbedingtes Beckenbodentrauma. Geburtsh Frauenheilk 2010; 70: 969-978

34 Abdool Z, Shek KL, Dietz HP. The effect of levator avulsion on hiatal dimension and function. Am J Obstet Gynecol 2009; 201: 89 e81-e85

35 Dietz HP, Franco AV, Shek KL et al. Avulsion injury and levator hiatal ballooning: two independent risk factors for prolapse? An observational study. Acta Obstet Gynecol Scand 2012; 91: 211-214

36 Kearney R, Miller JM, Delancey JO. Interrater reliability and physical examination of the pubovisceral portion of the levator ani muscle, validity comparisons using MR imaging. Neurourol Urodyn 2006; 25: 50-54

37 Weemhoff $M$, Vergeldt TF, Notten $K$ et al. Avulsion of puborectalis muscle and other risk factors for cystocele recurrence: a 2-year follow-up study. Int Urogynecol J 2012; 23: 65-71 